\title{
接触点形状による把握の安定性*
}

\author{
楯將 博*1, 舟 橋 康 行*2

\section{Grasping Stability Caused by the Curvatures at Contact Points}

\author{
Masahiro TATE and Yasuyuki FUNAHASHI
}

\begin{abstract}
In this paper we discuss the stability of the equilibrium grasp. We replace a grasp system with an elastic system, and we take into consideration the curvatures of fingers and objects. The potential energy function of this system is derived. The grasping stability is determined by the positive definiteness of the Hessian matrix of the potential function. Several numerical simulations show that the grasping stability depends greatly on the curvatures of both the grasped object and fingers.
\end{abstract}

Key Words: Robotics. Mechanics, Grasping Stability. Curvature at Contact Point, Potential Energy Function

\section{1. 緒}

ロボットハンドにより物体を把握するとき，その安 定性が問題となる。つまりロボットハンドが物体を把 握し系が釣合い状態にあるとき，その把握物体に対し ていかなる外乱が加わろうとも，その釣合い状態を維 持し続けることが可能か否かという問題である.

この問題の一つの解答は Form - closure grasp, Force-closure graspである(1)〜3). Form-closure grasp とは，ロボットハンドの指により物体を幾何学 的に拘束してしまう把握のことで，外乱が作用しても 物体は動かず把握が壊れることはない．またForce closure graspとは，指の押す力のみであらゆる方向 の力とモーメントを発生させることのできる把握のこ とで，外乱に対してそれを相殺する力が発生できるの で把握の維持は可能である。これらの把握では物体は 少しも変化しない，従って把握は安定である。

これに対して，把握物体の微小変化を許しその安定 性を考える研究がある。これはロボットハンドと把暒

* 傆稿受和 1995 年 2 月2 23 日。

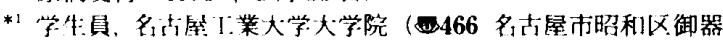
所町).

*2 IF是, 名古虐 I. 業大学。
物体をば权系に置き換え，そのポテンシャルエネルギ 一や復元力の観点から把握の安定性を議論するもので ある(4) (8).

これらの研究は大きく二つに分けることができる。 接触点で指が滑るか，滑らないかである，接触点間の 摩擦が十分大きいとすると，接触点で滑りは起こらな い、逆に摩擦が小さい，もしくは働かないとすると，滑 りを生ずる。この滑りの有無は安定性の解析に大きな 違いをもたらす．接触点が滑らないとすると，接触点 は物体表面上を動くことはない。したがって接触点の 位置のみが重要であり，接触点近傍の物体の形状や指 の)形状は，把握の安定性に影響を与えない。逆に滑り を許せば，接触点が物体と指の形状に沿って動くので， それらの形状が把握の安定性に影響を与える。

金子ら(4)はこの条件の違いにより，同じ把握が安定 にも不安定にもなることを示し，接触点が滑らない条 件のもとでの二次元の把握について解析を行ってい る。そこでは指の配置が与えられたとき，その把握が 安定になるために指の弾性が満たすべき条件を求めて いる。また三村ら(5)はこれを三次元空間での把握に拡 張して，同様の解析を行っている。

接触点が滑る条件のもとで, 花房ら(6)は安定な把握 を夷現する指の位置を求めている。そこではすべての 
指配置に対してポテンシャルエネルギーを求め，それ が極小となる指配置を安定な把握として求めている。

また Nguyen() は，釣合い状態にある把晊の安定性 について考察している。そこでは物体の形状を考慮し た把握系のポテンシャルエネルギーを考え，その一階 微分々二階微分の值から，その点が極小であるかを調 べることで，その釣合い状態が安定であるかを判定し ている。これにより接触点での物体の形状が，把握の 安定性に影響を与えていることを示した。

さらにHoward ${ }^{(8)}$ は，物体と指の雨方の形状を考慮 して，把握の安定性を復元力の観点から考察してい る.しかし接触点間に働く力の力学的解析が複雑であ る.

本稿では同様の問題をポテンシャルエネルギーの観 点から考察する。この観点により複雑な力学的解析を 回避することができる。本論文の特徵は，物体と指を 接触点での曲率円で近似することにより，接触の関係 を二つの円の関係に置き換えることにある。これによ り解析が簡単化されている。

本稿の構成は次のようになっている，第 2 章では釣 合い状態にある把握系のポテンシャルエネルギーを迹 き，さらに安定判別法を考える。第 3 章では計算例を 示し、いろいろな把握に対してその安定性を調べる。

\section{2. 把握系の安定性}

この章では把握系の安定性を議論するために，まず 把握系のポテンジャルエネルギーを導出し，次にその ポテンシャル関数を用いて平衡点(釣合い状態)での安 定性を調べる。

$2 \cdot 1$ 钎号図1に示すように記号を定義する. $\Sigma_{o}:$ 物体座標系

$\Sigma_{i}: i$ 番めの接触点近傍に設定した接触点座標系

$\boldsymbol{p}_{i}$ : 物体座標系と接触点座標系の相対位置

$\alpha_{i}:$ 物体座標系と接触点坐標系の相対角度

$R_{i}: i$ 番めの接触点での物体の曲率半径

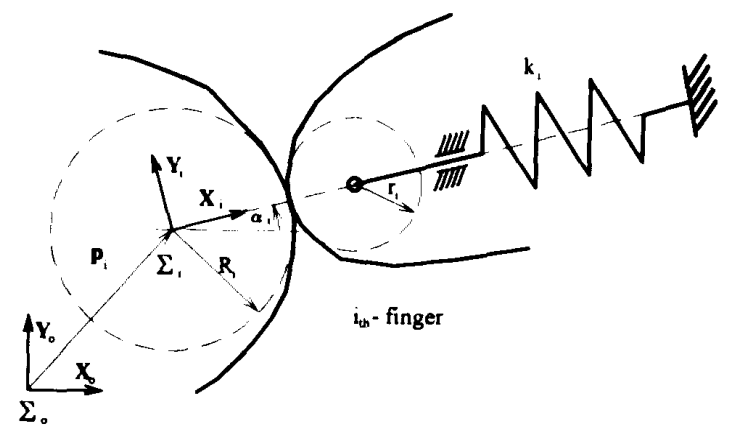

Fig. 1 Finger and object approximated by circles of curvature $r_{i}: i$ 番めの指先の曲率半径

$k_{i}$ : 指のばね定数

$\mathbf{2 \cdot 2}$ 仮定議論を簡単化するために以下の仮定 を設ける。

（1）指は図1のような1自由度のばねをもつ。

（2）物体と指の形状は既知で，接触点においてそ れぞれの曲率円で近似できる。

（3）釣含い状態にある指先(接触点) 位置, 指先力 は与えられている。

（4）各指と物体の接触点では摩擦は働かない。

仮定（1）のばねを設定することで，把握のポテンシ ヤルエネルギーを考えることができる、これはロボッ トのハードウェアによるばねのほかに，制御による仮 想的な弾性でもよい．仮定（2）は物体と指の接触点が 一点であることを意味する。またこの曲率円は形状を 2 次のオーダまで正確に記述することから，この仮定 は後に導くポテンシャルエネルギーの二階微分の值が 正確であることを保証する。仮定（３）は安定性を考察 する釣合い状態，すなわち平衡点を指定するものであ る.

$2 \cdot 3$ ポテンシャルエネルギー＼cjkstart把握系のポテン シャルエネルギーを考える。釣合い状態から外乱によ り第 $i$ 番めのば机に蓄えられる位置エネルギーは

$$
U=\Sigma U_{i}=\Sigma \frac{1}{2} k_{i}\left(s_{i o}+s_{i}\right)^{2}
$$

で与えられる。ここで $s_{i o}$ は物体に外乱が加わる前の 釣合い状態のばねの縮みであり，siは外乱によるばね の伸縮である。この $U i$ の総和は把握系全体のポテン シャルエネルギーである.

次に外乱による物体の姿勢変化と各指のばねの伸縮 $s_{i}$ との関係を調べる，そのためにまず各指の接触点座 標系で考察し，後に物体座標系に変換する。

$2 \cdot 3 \cdot 1$ 接触点座標系 図 2(a)のように物体と 指が両方とも凸の場合について考える，接触点座標系 を次のように定義する。まず物体を接触点での曲率円 で近似する。この曲率円の中心を座標系原点とし $X_{i}$ 軸を指のばねの縮み方向と一致させた座標系を接触点 座標系 $\Sigma_{i}$ とする。この接触点座標系を使って，物体の 動きとばねの伸縮の関係を調べる.

物体と同様に指についても接触点における曲率円で 近似する。このことにより物体と指の接触の関係は近 似した二つの円の関係で表現できる。いま物体と指の 曲率円の中心座標を $\left(A_{i}, B_{i}\right)^{T},\left(a_{i}, b_{i}\right)^{T}$ とすると, $\Sigma_{i}$ の定義から，外乱が加わる前のそれらの值は

$$
\left.\begin{array}{l}
\left(A_{i}, B_{i}\right)^{T}=(0,0)^{T} \\
\left(a_{i}, b_{i}\right)^{T}=\left(R_{i}+r_{i}, 0\right)^{T}
\end{array}\right\}
$$




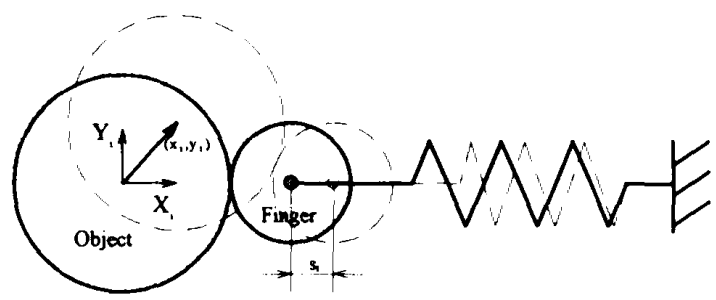

(a) Contact between convex object and convex fingertip

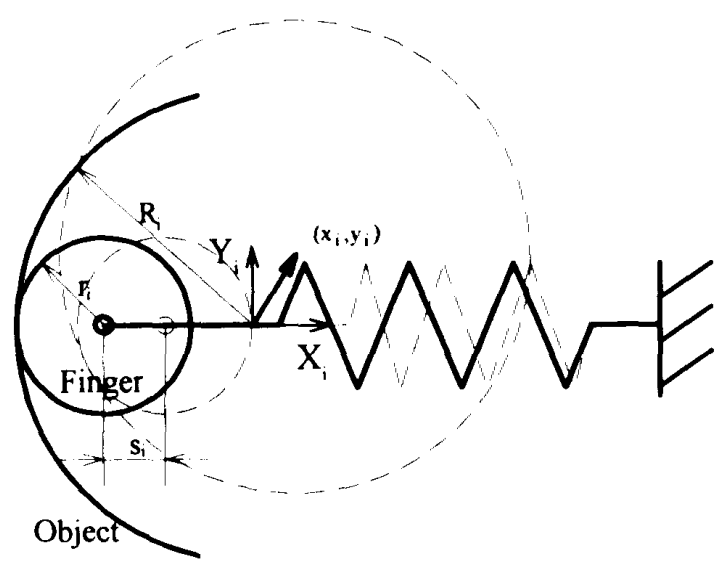

(b) Contact between concave object and convex fingertip

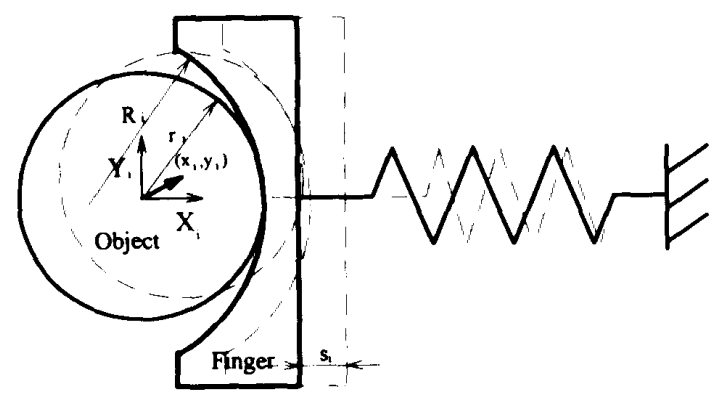

(c) Contact between convex object and concave fingertip

Fig. 2 Compression of virtual spring due to object displacement

になる。ここに外乱が作用して物体が動き，その結果 微小の並進変位 $\left(x_{i}, y_{i}\right)^{T}$ と回転変位 $\theta_{i}$ が接触点座標 系の原点に生じたとする。この動きに伴い各指のば权 が伸縮するが，接触点座標系の原点が曲率円の中心で あることを考えると，回転変位はばねの伸びに影響を 与えない，そこで並進変位のみの影響から式 (2)0)そ れぞれの值は次のように変化する。

$$
\left.\begin{array}{l}
\left(A_{i}, B_{i}\right)^{T}=\left(x_{i}, y_{i}\right)^{T} \\
\left(a_{i}, b_{i}\right)^{T}=\left(R_{i}+r_{i}+s_{i}, 0\right)^{T}
\end{array}\right\}
$$

物体と指が一点で接触し続けるためには，円の中心 間の距離が半径の和でなければならない。したがって 次の式を満足しなければいけない。

$$
\left(A_{i}-a_{i}\right)^{2}+\left(B_{i}-b_{i}\right)^{2}=\left(R_{i}+r_{i}\right)^{2}
$$

式(3)を式(4)に代入して $s_{i}$ について解くと.

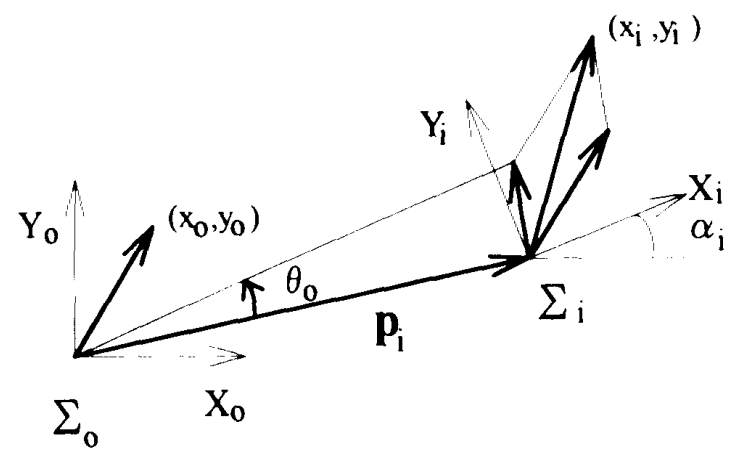

Fig. 3 Object and contact-point coodinate frames

$$
s_{i}=x_{i}-\left(R_{i}+r_{i}\right) \pm \sqrt{\left(R_{i}+r_{i}\right)^{2}-y_{i}^{2}}
$$

を得るが，物理的な意味を持つのは

$$
s_{i}=x_{i}-\left(R_{i}+r_{i}\right)+\sqrt{\left(R_{i}+r_{i}\right)^{2}-y_{i}^{2}}
$$

である。さらに $R_{i}+r_{i}>0$ より，

$$
s_{i}=x_{i}-\left(R_{i}+r_{i}\right)+\left(R_{i}+r_{i}\right) \sqrt{1-\left(\frac{y_{i}}{R_{i}+r_{i}}\right)^{2}}
$$

となる。これにより接触点座標系の原点における物体 の動き $\boldsymbol{x}_{i}=\left(x_{i}, y_{i}\right)^{T}$ とばねの伸縮 $s_{i}$ との関係が得ら れた。

ここでは図 2(a)のように接触点での形状が物体， 指のどちらとも凸の場合を扱ったが，どちらかが叫の 場合は図 $2(\mathrm{~b})$ ，（c）のようになり，同様の解析を行 うと式 $(7 \cdot \mathrm{a})$ に対応する次の式を得る(詳細は付録).

$$
\begin{aligned}
& s_{i}=x_{i}-\left(-R_{i}+r_{i}\right)+\left(-R_{i}+r_{i}\right) \\
& \times \sqrt{1-\left(-\frac{y_{i}}{-R_{i}+r_{i}}\right)^{2}} \\
& s_{i}=x_{i}-\left(R_{i}-r_{i}\right)+\left(R_{i}-r_{i}\right) \sqrt{1-\left(\frac{y_{i}}{R_{i}-r_{i}}\right)^{2}}
\end{aligned}
$$

この結果を式 $(7 \cdot a)$ と比較すると, 形状が凹の場合は 曲率半径の符号を負とすればよいことがわかる。

$2 \cdot 3 \cdot 2$ 物体座標系 $2 \cdot 3 \cdot 1$ 項では接触点座標系 での物体の動きとば权の伸縮の関係を求めた。次に物 体座標系での物体の動きとば极の伸縮の関係を調べる ために，接触点座標系での物体の動きと物体座標系で の物体の動きが、どのような関係にあるのかを調べ る。

そのために物体の任意の位置に物体座標系 $\Sigma_{0}$ を設 定する. 外乱により物体に $\boldsymbol{x}_{o}=\left(x_{0}, y_{0}\right)^{T}$ の並進变位 と， $\theta_{0}$ の回転変位が物体座標系 $\Sigma_{0}$ の座標系原点にお いて発生したとする。このとき物体座標系 $\Sigma_{o}$ から $\boldsymbol{p}$ ， $=\left(p_{i x}, p_{i y}\right)^{T}$ の位置にある接触点座標系 $\Sigma_{i}$ O) 座標系 原点において，物体は次のような並進変位をもつ(図 3 ). 
$\boldsymbol{x}_{o}+\left(\operatorname{Rot}\left(\theta_{o}\right)-I_{2}\right) \boldsymbol{p}_{i}$

ここで $I_{2}$ は 2 次の単位行列である.また Rot $(・)$ は回 転行列であり次のように表せる。

$$
\operatorname{Rot}(\cdot)=\left[\begin{array}{lr}
\cos (\cdot) & -\sin (\cdot) \\
\sin (\cdot) & \cos (\cdot)
\end{array}\right]
$$

この並進変位は物体座標系での值である。これを接 触点座標系 $\Sigma_{i}$ で表すと， $\Sigma_{i}$ と $\Sigma_{o}$ との相対角度 $\alpha_{i}$ を 使って次のようになる。

$$
\boldsymbol{x}_{i}=\operatorname{Rot}\left(-\alpha_{i}\right)\left\{\boldsymbol{x}_{o}+\left(\operatorname{Rot}\left(\theta_{o}\right)-I_{2}\right) \boldsymbol{p}_{i}\right\}
$$

これが物体の動きの物体座標系での值 $\left(x_{o}, \theta_{o}\right)$ と接触 点座標系での值 $\boldsymbol{x}_{i}$ との関係式である.この式(9)を 式（７）に代入することで，物体座標系での物体の動き とばねの伸縮の関係が解る。さらに式(1)に代入する ことによって $U_{i}$ が $x_{o}, y_{o}, \theta_{o}$ で表せる.つまり外乱に よる物体の動きとポテンシャルエネルギーの関係がわ かる.

$\mathbf{2 \cdot 4}$ 把提の安定性 $2 \cdot 3$ 節で求めたホテンシャ ル関数を使い, 釣合い状態にある把握の安定性につい て考える、一般にある状態が安定であるためには，そ の現象を支配する関数がその点を平衡点(傾き需) とし てもち，さらにそれが安定な平衡点(下に凸)でないと いけない. 本稿では外乱なしの状態 $\left(x_{o}=y_{o}=\theta_{o}=0\right)$

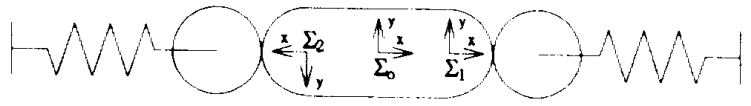

(a) A convex object grasped by convex fingertips

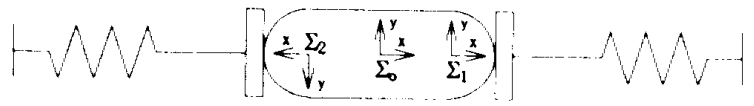

(b) A convex object grasped by flat fingertips

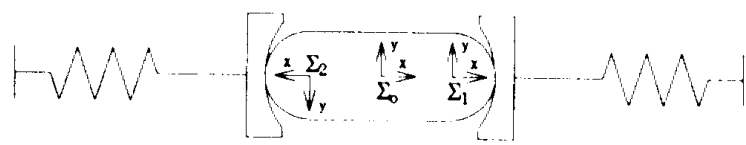

(c) A convex object grasped by concave fingertips

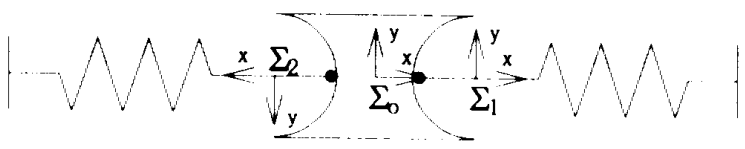

(d) A concave object grasped by sharp fingertips

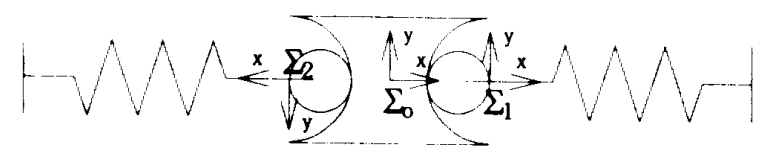

(e ) A concave object grasped by small fingertips
が釣合い状態であり，平衡点であることが仮定 (3)で 保証されているので、この点でポテンシャル関数が下 に凸であるのかを調べればよい。つまり以下で与えら れるHessian 行列の正定性を調べればよい.

$$
\boldsymbol{H}=\left[\begin{array}{ccc}
\frac{\partial^{1} U}{\partial x_{o}^{2}} & \frac{\partial^{2} U}{\partial x_{o} \partial y_{o}} & \frac{\partial^{2} U}{\partial x_{o} \partial \theta_{o}} \\
\frac{\partial^{2} U}{\partial x_{o} \partial y_{o}} & \frac{\partial^{2} U}{\partial y_{o}^{2}} & \frac{\partial^{2} U}{\partial y_{o} \partial \theta_{o}} \\
\frac{\partial^{2} U}{\partial x_{o} \partial \theta_{o}} & \frac{\partial^{2} U}{\partial y_{o} \partial \theta_{o}} & \frac{\partial^{2} U}{\partial \theta_{o}^{2}}
\end{array}\right]
$$

ここで $\boldsymbol{H}$ の各要素の值は, 式 (1)，（7），(9)加次 のようになる。

$$
\begin{aligned}
& \left.\frac{\partial^{2} U}{\partial x_{o}^{2}}\right|_{\substack{x_{o}=0 \\
y_{o}=0}}=\Sigma\left\{k_{i} \cos ^{2} \alpha_{i}-\frac{k_{i} s_{i o}}{r_{i}+R_{i}} \sin ^{2} \alpha_{i}\right\} \\
& \left.\frac{\partial^{2} U}{\partial x_{o} \partial y_{o}}\right|_{\substack{x_{o}=0 \\
y_{o}=0 \\
\theta_{o}=0}}=\sum\left\{k_{i} \frac{\left(r_{i}+R_{i}+s_{i o}\right)}{2\left(r_{i}+R_{i}\right)} \sin 2 \alpha_{i}\right\} \\
& \left.\frac{\partial^{2} U}{\partial x_{O} \partial \theta_{o}}\right|_{\substack{x_{0}=0 \\
y_{o}=0 \\
\theta_{0}=0}}=\sum\left\{k_{i}\left(-p_{i y} \cos \alpha_{i}+p_{i x} \sin \alpha_{i}\right) \cos \alpha_{i}\right.
\end{aligned}
$$

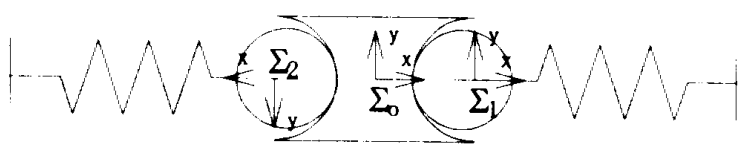

(f) A concave object grasped by large fingertips

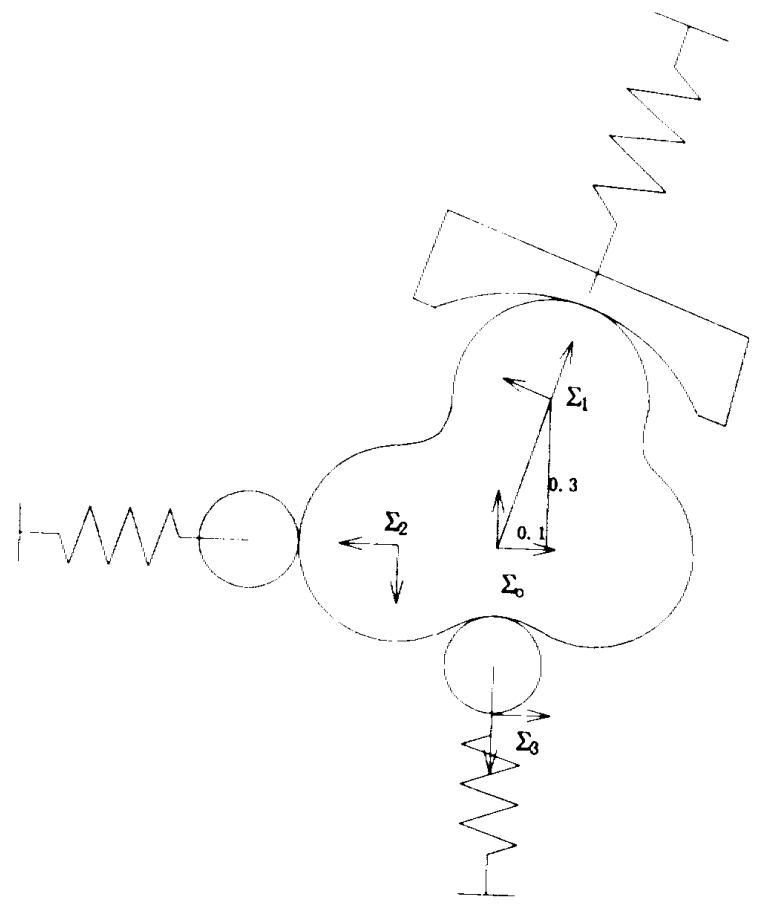

(g) An object grasped by three fingertips

Fig. 4 Stability of grasps 
$\left.+\frac{k_{i} s_{i o}}{r_{i}+R_{i}}\left(p_{i y} \sin \alpha_{i}+p_{i x} \cos \alpha_{i}\right) \sin \alpha_{i}\right\}$

$$
\begin{aligned}
& \left.\frac{\partial^{2} U}{\partial y_{0}^{2}}\right|_{x_{0}=0}=\sum\left\{k_{i} \sin ^{2} \alpha_{i}-\frac{k_{i} s_{i o}}{r_{i}+R_{i}} \cos ^{2} \alpha_{i}\right\} \\
& -\left.\frac{\partial^{2} U}{\partial y_{o} \partial \theta_{o}}\right|_{\substack{x_{o}=0 \\
y_{o}=0}}=\Sigma\left\{k_{i}\left(-p_{i y} \cos \alpha_{i}+p_{i x} \sin \alpha_{i}\right) \sin \alpha_{i}\right. \\
& \left.-\frac{k_{i} s_{i o}}{r_{i}+R_{i}}\left(p_{i y} \sin \alpha_{i}+p_{i x} \cos \alpha_{i}\right) \cos \alpha_{i}\right\} \\
& \left.\frac{\partial^{2} U}{\partial \theta_{o}^{2}}\right|_{\substack{x_{o}=0 \\
y_{o}=0 \\
\boldsymbol{\theta}_{0}=0}}=\Sigma\left\{k_{i}\left(-p_{i y} \cos \alpha_{i}+p_{i x} \sin \alpha_{i}\right)^{2}\right. \\
& -\frac{k_{i} S_{i o}}{r_{i}+R_{i}}\left(p_{i y} \sin \alpha_{i}+p_{i x} \cos \alpha_{i}\right)^{2} \\
& \left.-k_{i} s_{i o}\left(p_{i y} \sin \alpha_{i}+p_{i x} \cos \alpha_{i}\right)\right\}
\end{aligned}
$$

式中の $k_{i}, s_{i o}$ は釣合い状態における各指のばね定数 と力の大きさから， $\alpha_{i}, \boldsymbol{p}_{i}, r_{i}, R_{i}$, は物体と指の形状と 接触点の位置からその值がわかり, 数值的に $\boldsymbol{H}$ の固 有值を求め，その正負を調べすべてが正であれば正定 であり、把握系は安定である。

この方法を用いれば，物体と指の形状を考虑した把 暒の安定性を調べることができる。

\section{3. 部 算 例}

この章では 2 章の方法を使って, 図 4 のいろいろな 把握の安定性を調べる。表 1 に計算に必要な值と求め たHessian 行列の固有值を示す.

Case ( a ) 〜 ( c ) は物体の凸の部分を 2 本指で把摬
したとき，その指先の形状により把搉の安定性がどう 変化するのかを調へたたものである。（b）のように指が 平面の場合，その曲率半径は無限大なので極限をとる ものとする。

表 1 からわかることは物体を凸の部分でもつとき は，(c)のように指先が凹になっていないと不安定に なるということである.この結果は直感にあう。

Case $(\mathrm{d})$ （f ) は物体の山の部分を 2 本指で把握 したときに，その指先の形状により把握の安定性がど のように変化するのかを調べたものである。(d)のよ うに指先が点の場合(先が尖っている状態など)は，そ の曲率半径は零である。

表1からわかることは物体の凹部分で把握を行うと 安定になることである，さらに指が大きくなるほど固 有值が大きくなっていることがわかる．このことは指 が大きいほうがより安定であることを示している。

Case ( $\mathrm{g}$ ) 江 3 本指で把握したときの安定性を調べ ている。この把暒は固有值がすべて正なので安定であ ることがわかった。このように本手法では 3 本指での 把握の安定性をも調べることができ，さらに $n$ 本指に ついても可能である。

\section{4. 結}

本稿は釣合い状態にある把握の安定性について議論 した、ロボットハンドと把暒物体を等価なばね系に置 き換え，物体と指の形状を考虑したポテンシャルエネ ルギーを導出し，それを用いて把握の安定判別法を考 察した。また数值例によりその安定性が接触点におけ る物体とロボットハンドの形状 (曲率)に大きく依存し

Table 1 Numerical examples

\begin{tabular}{|c|c|c|c|c|c|c|c|c|}
\hline \multirow{2}{*}{$\begin{array}{c}\text { Case } \\
\text { Fig. }\end{array}$} & \multirow{2}{*}{ Finger } & \multicolumn{2}{|c|}{ Finger's } & \multicolumn{2}{c|}{ Finger's } & \multicolumn{2}{c|}{ Curvature of } & Eigenvalues \\
& & \multicolumn{2}{|c|}{ Force } & \multicolumn{2}{c|}{ Angle $\&$ Position } & Finger & \& Object & Stability \\
\cline { 3 - 8 } & $k_{i}$ & $s_{i o}$ & $\alpha_{i}$ & $\left(p_{i x}, p_{i y}\right)$ & $r_{i}$ & $R_{i}$ & \\
\hline (a) & 1 & 1 & 0.01 & 0 & $(0.2,0.0)$ & 0.1 & 0.1 & $(2.0,-0.1,-0.008)$ \\
& 2 & 1 & 0.01 & $\pi$ & $(-0.2,0.0)$ & 0.1 & 0.1 & Unstable \\
\hline (b) & 1 & 1 & 0.01 & 0 & $(0.2,0.0)$ & $\infty$ & 0.1 & $(2.0,0.0,-0.004)$ \\
& 2 & 1 & 0.01 & $\pi$ & $(-0.2,0.0)$ & $\infty$ & 0.1 & Unstable \\
\hline (c) & 1 & 1 & 0.01 & 0 & $(0.2,0.0)$ & -0.2 & 0.1 & $(2.0,0.2,0.004)$ \\
& 2 & 1 & 0.01 & $\pi$ & $(-0.2,0.0)$ & -0.2 & 0.1 & Stable \\
\hline (d) & 1 & 1 & 0.01 & 0 & $(0.2,0.0)$ & 0.0 & -0.1 & $(2.0,0.4,0.008)$ \\
& 2 & 1 & 0.01 & $\pi$ & $(-0.2,0.0)$ & 0.0 & -0.1 & Stable \\
\hline (e) & 1 & 1 & 0.01 & 0 & $(0.2,0.0)$ & 0.05 & -0.1 & $(2.0,0.8,0.024)$ \\
& 2 & 1 & 0.01 & $\pi$ & $(-0.2,0.0)$ & 0.05 & -0.1 & Stable \\
\hline (f) & 1 & 1 & 0.02 & 0 & $(0.2,0.0)$ & 0.09 & -0.1 & $(2.0,2.0,0.076)$ \\
& 2 & 1 & 0.02 & $\pi$ & $(-0.2,0.0)$ & 0.09 & -0.1 & Stable \\
\hline (g) & 1 & 1 & $1.00 \mathrm{e}-2$ & $3 \tan ^{-1} 3$ & $(0.1,0.3)$ & -0.4 & 0.2 & $(2.0,1.1,0.0086)$ \\
& 2 & 1 & $3.16 \mathrm{e}-3$ & $\pi$ & $(-0.2,0.0)$ & 0.1 & 0.2 & Stable \\
& 3 & 1 & $9.49 \mathrm{e}-3$ & $3 \pi / 2$ & $(0.0,-0.2 \sqrt{3})$ & 0.1 & -0.2 & \\
\hline
\end{tabular}


ていることを示した。

最後に本研究について熱心に御討論いただいた(株) 豊田中央研究所三村宣治氏, 名古屋工業大学大学院山 田貫孝氏，鉿木泰充氏に感謝の意を表する。

\section{付録}

どちらか一方の接触点形状が凹の場合について考え る.

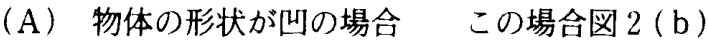
のようになっているので一点で接触するための条件は

$\left(A_{i}-a_{i}\right)^{2}+\left(B_{i}-b_{i}\right)^{2}=\left(-R_{i}+r_{i}\right)^{2}$

になる.ここに外乱が作用して物体が動き，その結果 曲率円の中心が $\left(x_{i}, y_{i}\right)^{T}$ だけ動くと

$$
\left.\begin{array}{l}
\left(A_{i}, B_{i}\right)^{T}=\left(x_{i}, y_{i}\right)^{T} \\
\left(a_{i}, b_{i}\right)^{T}=\left(-R_{i}+r_{i}+s_{i}, 0\right)^{T}
\end{array}\right\}
$$

これを式(11)に代入して $s_{i}$ について解くと

$$
s_{i}=x_{i}-\left(-R_{i}+r_{i}\right) \pm \sqrt{\left(-R_{i}+r_{i}\right)^{2}-y_{i}^{2}}
$$

となる，物理的な意味をもつのは

$$
s_{i}=x_{i}-\left(-R_{i}+r_{i}\right)-\sqrt{\left(-R_{i}+r_{i}\right)^{2}-y_{i}^{2}}
$$

である。さらに $-R_{i}+r_{i}<0 よ り$

$$
\begin{aligned}
s_{i} & =x_{i}-\left(-R_{i}+r_{i}\right)+\left(-R_{i}+r_{i}\right) \\
& \times \sqrt{1-\left(\frac{y_{i}}{-R_{i}+r_{i}}\right)^{2}} \quad \ldots \ldots \ldots \ldots . .
\end{aligned}
$$

となる。この式を本文中の式 $(7 \cdot a)$ と比較すると物体 側の曲率半径の符号が負になっていることがわかる。

（B）指の形状が山の場合この場合図 2 (c)の ようになっているので，一点を接触するための条件は

$\left(A_{i}-a_{i}\right)^{2}+\left(B_{i}-b_{i}\right)^{2}=\left(R_{i}-r_{i}\right)^{2}$

$$
\left.\begin{array}{l}
\left(A_{i}, B_{i}\right)^{T}=\left(x_{i}, y_{i}\right)^{T} \\
\left(a_{i}, b_{i}\right)^{T}=\left(R_{i}-r_{i}+s_{i}, 0\right)^{T}
\end{array}\right\}
$$

になり。これを式(15)に代人して $s_{i}$ について解くと

$$
s_{i}=x_{i}-\left(R_{i}-r_{i}\right) \pm \sqrt{\left(R_{i}-r_{i}\right)^{2}-y_{i}^{2}}
$$

となるが、物理的な意味をもつのは

$$
s_{i}=x_{i}-\left(R_{i}-r_{i}\right)-\sqrt{\left(R_{i}-r_{i}\right)^{2}-\overline{y_{i}^{2}}}
$$

である。さらに $R_{i}-r_{i}<0 よ り$

$$
s_{i}=x_{i}-\left(R_{i}-r_{i}\right)+\left(R_{i}-r_{i}\right) \sqrt{1-\left(\frac{y_{i}}{R_{i}-r_{i}}\right)^{2}}
$$

となる。この式を本文中の式 $(7 \cdot \mathrm{a})$ と比較すると指側 の曲率半徍の符号が負になっていることがわかる。

\section{文献}

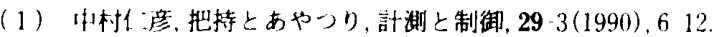

(2) Nguyen, V. D.. Constructing Force-Closure Grasps, Int. J. of Robotics Research, 7-3(1988), 316.

(3) Markenscoff, X., Ni, L. and Papadimitriou, C., The Geometry of Grasping, The Int. J. of Robotics Research, 9-1(1990), 61-74

（4）金子 真・令村信昭・横井一伝・谷汇和雄，摩擦を考虑し た多指ハンドの剛性モデルによる安芫把剭解析,JRSJ，7 $3(1989), 4959$

（5）三村宣治・舟橋康行，刪性を有する3 本指ハンドによる三 次元物体U)安足把提解析，機論，57 537，C(1991)，213 220 .

（6）花房秀郎・浅出春比古，弹性指を伯するロボットハンドに 上る物体の安定な把揞，計測自動制御学会論文集，134 (1977), 5865

( 7 ) Nguyen, V. D., Constructing Stable Grasps, The Int. J. of Robotics Research. 8-1(1989), 26-37.

(8) Howard, W. S. and Kumar, V.. Stability of Planar (irasps, Proc. 19944 IEEE Int. Conf. on Robotics and Autom., (1994), 28222827.

外乱が作用した後, 中心座標は 